Academic Platform Journal of Engineering and Science

\title{
Kararsız Koşullarda SMDA Motorun Dayanıklı Hız Kontrolü için Bulanık-Tabanlı Akıllı Denetleyici Tasarımı
}

\author{
${ }^{* 1}$ Murat Tuna

\begin{abstract}
${ }^{1}$ Kırklareli Üniversitesi, Teknik Bilimler MYO, Elektrik ve Enerji Bölümü, Kırklareli, murat.tuna@klu.edu.tr,
Araștırma Makalesi

Geliş Tarihi: 11.12 .2019

Kabul Tarihi: 27.02.2020
\end{abstract}

$\ddot{O} \mathbf{z}$

Bu çalışmada, sabit ve değişken yükler altında doğrusal olmayan referans hızlarda çalışan SMDA motorun bulanık mantık tabanlı akıllı ve dayanıklı hız kontrolör tasarımı gerçekleştirilmiştir. Akıllı kontrol, insanın bulucu ve uyarlayıcı davranışlarını taklit edebilecek niteliğe sahip sistemler geliştirmeyi hedeflemektedir. Tasarlanan akıllı kontrol teknikleri; Bulanık Mantık denetleyici (BMD), oransal-integral (PI) tipli BMD ve Kendini Ayarlayan (Öz uyarlamalı) Bulanık PI (KABPI) denetleyicidir. Kontrol algoritmasının amacı, rotor hızının istenen referans hızını her zaman güçlükle takip etmeye zorlamaktır. Bu amaca, yükte bozulma ve parametre değişikliklerinden bağımsız olarak farklı hız/zaman değişimleri içinde ulaşılmalıdır. Tasarlanan denetleyicilerin kararsız çalışma koşulları altında dayanıklı hız denetimi üzerindeki performansları karşılaştırılmış ve alınan sonuçlar tartışılmıştır. Elde edilen karşılaştırma ve benzetim sonuçlarına göre, KABPI kontrol yöntemi istenen kontrol kriterlerini karşılamada diğerlerine nazaran daha iyi sonuçlar göstermiştir.

Anahtar Kelimeler: SMDA motor, PI, bulanık mantık denetleyici, hız kontrol, akıllı kontrol tasarımı

\section{Fuzzy-Based Intelligent Controller Design for Robust Speed Control of PMDC Motor in Unstable Conditions}

\author{
*11Murat Tuna \\ ${ }^{1}$ Kirklareli University, Vocational School of Technical Sciences, Department of Electricity and Energy, Kırklareli, \\ murat.tuna@klu.edu.tr
}

\begin{abstract}
In this study, the Fuzzy Logic based smart and durable speed controller design of PMDC motor at non-linear reference speeds under constant and variable loads are realized. Intelligent control methods aim to develop systems capable of imitating human's intuitive and conscious behavior. The designed control methods are: Fuzzy Logic controller (FLC), proportional-integral (PI) type FLC (FLCPI) and Self-Tuning Fuzzy PI (STFPI) controllers. The purpose of the control algorithm is to force the speed of the motor to always follow the desired reference speed. The designed controller must meet this request for different speed / time changes, regardless of load failure and parameter changes. The performances of the controllers on durable speed control under unstable operating conditions have compared and the results obtained have discussed. According to the comparison and simulation results obtained, the STFPI control method showed better results than others in meeting the desired control criteria.
\end{abstract}

Keywords: PMDC motor, PI, fuzzy logic controller, speed control, intelligent control design

\section{GİRIŞ}

Sabit mıknatıslı DA motorlar (SMDA) yüksek verim, yüksek moment ve düşük ses seviyeleri sayesinde güvenli ve dayanıklı kontrol sistemlerinin en önemli parçasıdırlar [1],
[2]. $\mathrm{Bu}$ motorlar yüksek moment/akım ve moment/eylemsizlik oranı, sağlam yapı, yüksek verim, sürekli kontrol özellikleri ve güvenirlik gibi üstünlüklerinden dolayı endüstride ani yük bozulmasına maruz kalan PV pompalama sistemleri [3], tekerlekli 
sandalye [4], elektrikli otomobiller [5], robot manipülatörleri [6], robotik tutucu [7] ve güneş izleyicileri [8] gibi uygulamalarda kullanılmaktadir [9], [10]. Motor kontrolünde karşılaşılan problemler çalışma koşulları altında motor parametrelerinin zamanla değişen doğası ve sistem döngüsü içindeki gürültünün varlığıdır. Motorun elektriksel parametreleri sıcaklık, akım ve gerilim dalgalanmaları, zamana göre değişen yükleme koşulları, sürüş ve çalışma koşullarına göre değişmekte ve buda rotor hızında dalgalanmalar meydana getirmektedir [11]. Geleneksel PI metotlar farklı atalet, yük ve hız referanslarında beklenen optimum cevabı veremeyip dayanıklı hız kontrolü için istenen kriterleri karşılayamamaktadır [12]. Bu nedenledir ki kompleks, lineer olmayan ve/veya zamanla değişen sistemlerin analiz ve kontrolünde geleneksel metotların belirsizliğinden dolayı endüstrideki kullanımın yoğunluğu değiştirmiştir [13].

Dayanıklı hız kontrolünden beklenen;

- Birim değerde ölçülen motor hız eğrisinin maksimum aşma değeri (Maximum overshot $(\mathbf{M p}<\mathbf{1 0 \%})$ ),

- Referans hız ile motor çıkış hızı arasında hata (No steady-state-error $(\boldsymbol{e s s}<\mathbf{1 \%} \%)$,

- Motor hı eğrisinin sabit durum değerinin mutlak yüzdesiyle belirtilen son büyüklük değeri civarında olması ve bu aralıkta kalması için gereken süre (Setting time $(\boldsymbol{t s}<\mathbf{2} \mathbf{s}))$,

- Motor hızının ilk defa sabit değerinin yarısına ulaşması için gereken süre (Delay time $(\boldsymbol{t} \boldsymbol{d})$ ),

- Motor hızının sabit durum değerinin \%10'dan \%90'a yükselmesi için gereken süre (rising time $(\boldsymbol{t r}<\mathbf{1 s})$ ),

olarak tanımlanan performans kriterlerine uygun olarak doğrusal olmayan çalışma ve yük koşulları altında istenen referans hıza en iyi cevabı vermesidir [14]. İkinci dereceden doğrusal zamanla değişmeyen bir sistemin $M p$, ess, $t s, t d$ ve tr değerlerini gösteren tipik bir adım cevabı Şekil 1'de gösterilmiştir. İstenen bu kriterleri farklı referans hızlarda ve değişken yük koşullarında sağlamak ve hız cevabını geliştirmek için geleneksel PID denetleyicinin yerine bulanık tabanlı akıllı denetleyiciler kullanmak gereklidir [15]. Bulanık mantık kontrolü, birçok mühendislik alanındaki geleneksel kontrol stratejilerine alternatif veya tamamlayıcı olarak ortaya çıkmıştır [16].

Sistem belirsizliklerinin üstesinden gelen ve Bulanık Kontrol olarak adlandırılan bu yöntemi ilk defa 1965'te Zadeh tarafindan ileri sürülmüştür [17]. Bulanık tabanlı kontrolün en önemli avantajlarından biri, sistemin herhangi bir matematiksel modeli olmaksızın kontrol mühendisliği bilgisi veya uzman deneyimleri kullanılarak doğrusal olmayan kompleks sistemlerin kontrolünü başarılı bir şekilde gerçekleştirmesidir [18], [19]. Doğrusal olmayan sistemlerin tanımlanması ve kontrolünde sistem teorisi ve kararlılık şartları yeterince geliştirilmemiştir. Bununla birlikte kontrol edilecek sistemlerdeki belirsizlikleri ve dinamik davranışlarındaki değişiklikleri tanımlamak için akıllı kontrol yöntemlerine yönelik çalışmalar artmıştır [20], [21].
Akıllı kontrol insanın uyarlayıcı davranışlarını taklit edebilecek niteliğe sahip sistemler geliştirmeyi hedeflemektedir. Akıllı kontrol zamanla değişen, iyi tanımlanmamış ortamlarda çalışan, ortamda ve sistem dinamiklerindeki değişimlere kendini uyarlayan ve sistem dinamikleri üzerine çok az kısıtlama gerektiren algoritmalara ihtiyaç duyarlar.

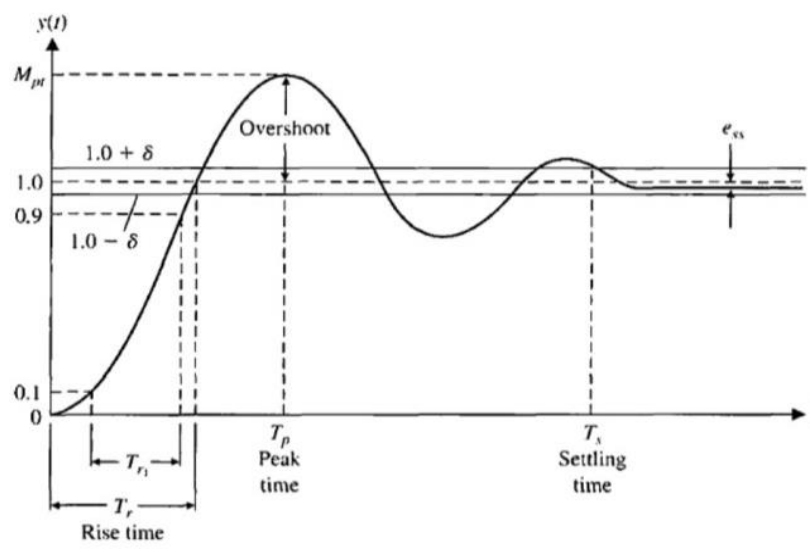

Şekil 1. İkinci dereceden bir sistemin doğrusal zamanla değişmeyen adım tepkisindeki kontrol parametreleri.

DA motor kontrolünde Bulanık mantık tabanlı sistemlerle yapılan akıllı kontrol uygulamaları gün geçtikçe artmaktadır [22]. Babu ve diğerleri yaptıkları çalışmada, DA motorun hız kontrolünde kullanılan P-I, I-P, PID ve Bulanık tabanlı yöntemlerin performans karşılaştırmalarını yaparak BMD yönteminin aşma miktarını bitirdiğini ve oturma zamanını çok daha azalttığını göstermişlerdir [23]. Khuntia ve arkadaşları yaptıkları çalışmalarında DA motor hız kontrolü için P-I, I-P, Bulanık ve Yapay-Bulanık kontrol yöntemlerini karşılaştırarak Bulanık-tabanlı kontrol yöntemlerin daha iyi sonuçlar verdiğini gözlemlemişlerdir [24]. Varshney ve arkadaşları ise fırçasız DA motorun değişen yük koşulları altındaki hız kontrolü için geleneksel PID ve Bulanık PID kontrol yöntemlerinin karşılaştırmasını yapmışlardır [25]. Premkumar ve diğerleri yaptıkları çalışmada, firçasız DA motorun hız kontrolü için bulanık orantılı türev denetleyici ve bulanık orantılı türev bütünleşik denetleyici tasarımını sunmuşlardır. Ayrıca denetleyicilerin tasarım optimizasyonunda parçacık sürüsü, guguklu arama ve yarasa algoritmaları gibi doğadan ilham alan optimizasyon algoritmalarını kullanılarak gerçekleştirmişlerdir [26]. Diğer bir çalışmada Arulmozhiyal gömülü entegre sistemler üzerinde değişen yük koşulları altında fırçasız DA motor hız denetimi için gömülü sistem tabanlı Bulanık-PID kontrolör tasarımını gerçekleştirmiştir [27]. Ayrıca geleneksel PID ile karşılaştırarak Bulanık-PID denetleyicinin daha iyi kontrol performansı sergilediğini göstermiştir. Bu çalışmada, farklı çalışma koşullarında dayanıklı hız denetleyici tasarlamak amaciyla motor kontrolünde kullanılan geleneksel PI ve BMD tabanlı akıllı kontrol tekniklerinin performansları karşılaştırılmıştır. Ayrıca BMD kontrolünde durulama kısmında kullanılacak olan en uygun duruluma yöntemi farklı referans hızlarda karşılaştırma yapılarak sunulmuştur. 
SMDA motorun modeli Matlab/Simulink programında simule edilerek, sabit ve doğrusal olmayan referans değerler uygulanmış ve motor çıkış hızının giriş referansına yaklaşımı incelenmiştir.

\section{MALZEME VE YÖNTEM}

\subsection{SMDA Motorun Dinamik Analizi}

SMDA motoru bir motorda arzu edilen birçok özelliğe sahiptir. Bunlardan bazıları güvenli, dayanıklı, maliyetinin düşük olması, kolay kontrol edilebilmesi ve bunların yanında düşük gerilimlerde çalışabilmesidir. $\mathrm{Bu}$ nedenle $\mathrm{DA}$ motorlar birçok uygulamada tercih edilirler. SMDA motor, DA motor türlerinden biri olup gerilim kaynağından sağlanan elektrik enerjisini manyetik eşleme yöntemi ile dönen rotor vasıtasıyla mekanik enerjiye dönüştürür.

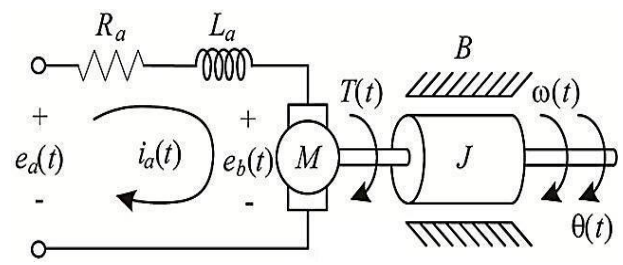

Şekil 2. SMDA motor şeması [28].

Şekil 2'de gösterilen motorun matematiksel ifadesi kontrol sisteminin değişkenleri olan endüvi akımı $i_{a}$ ve açısal hız $w_{m}$ için durum uzayı biçimde,

$\frac{d}{d t}\left[\begin{array}{c}i_{a} \\ w_{m}\end{array}\right]=\left[\begin{array}{rr}-\frac{R_{a}}{L_{a}} & -\frac{k}{L_{a}} \\ \frac{k}{J m} & -\frac{B}{J m}\end{array}\right] *\left[\begin{array}{c}i_{a} \\ w_{m}\end{array}\right]+\left[\begin{array}{c}\frac{1}{L_{a}} \\ 0\end{array}\right] * V_{a}-\left[\begin{array}{c}0 \\ \frac{1}{J m}\end{array}\right] * T_{L}$

(1) deki gibi ifade edilmektedir. Burada;

$$
\begin{aligned}
V_{a} & =\text { Armatür gerilimi }(\mathrm{V}) \\
R_{a} & =\text { Armatür direnci }(\Omega) \\
i_{a} & =\text { Armatür akımı }(\mathrm{A}) \\
L_{a} & =\text { Armatür indüktansı }(\mathrm{H}) \\
e_{b} & =\text { Zit emk }(\mathrm{V}) \\
w_{m} & =\text { Açısal hız }(\mathrm{rad} / \mathrm{s}) \\
K_{t} & =\text { Moment sabiti }(\mathrm{Nm} / \mathrm{A}) \\
K_{b} & =\text { Zit emk sabiti }(\mathrm{Vs} / \mathrm{rad}) \\
J_{m} & =\text { Rotor ataleti }\left(\mathrm{kgm}^{2}\right)
\end{aligned}
$$

$$
\begin{aligned}
B & =\text { Viskoz sürtünme katsayısı }(\mathrm{Nms} / \mathrm{rad}) \\
T_{L} & =\text { Yük momenti }(\mathrm{Nm}) \\
T & =\text { Motor momenti }(\mathrm{Nm})
\end{aligned}
$$

\subsection{Bulanık Mantık Denetleyici}

Son yıllarda, bulanık denetleyiciler endüstriyel uygulamalarda oldukça yaygın kullanım alanı bulmaktadır. Bulanık denetleyicinin en önemli özelliği, uzman bilgisine dayalı dilsel denetimleri IF-THEN kuralları ile otomatik denetim sistemine aktarmasıdır. Bulanık kontrol, operatörün sistem üzerindeki deneyimlerini de göz önünde bulundurarak, dilsel ifadeleri ile bulanıklaştırma, kural tabanı ve durulaştırma mekanizmalarını kullanarak kontrol işlemini yerine getirir [29], [30]. Bulanık kuralları belirleyebilmek için sistemin çıkış cevabı değişik noktalarda analize tabi tutularak elde edilir. Bu tür sistemler, "Kural tabanlı bulanık sistemler" olarak adlandırılır [31]. Bulanık sistemler, modelleme, veri çözümlemesi, kestirim ve kontrol gibi farklı amaçlar için kullanılabilirler. En basit bulanık sistemin ana yapıları bulanık kural tabanı ve çıkarım mekanizmasıdır. Kural tabanında, bulanık IF-THEN kuralları bulunur. Kural tabanı ve çıkarım mekanizmasından oluşan temel bulanık sistemi, ayrıca bulandırıcı ve durulayıcı adı verilen iki birim daha içermektedir. Bulandırıcı gerçel değerli sistem girişini bulanık kümelere dönüştürürken, durulayıcı ise tersine, çıkarım mekanizmasının ürettiği bulanık kümeleri gerçel değerli sistem çıkışına dönüştürmektedir. Sezgi ve tecrübeyi bulanık denetim algoritmasında uygun bir şekilde birleştirip kullanmak için hata işaretinin dinamik davranışının önceden bilinmesi gerekmektedir. Analizi daha da kolaylaştıran genel rotor hız tepkisi Şekil 3'te verilmiştir. Motorun dinamik işaret analizinde kullanılan formüller,

$$
\begin{aligned}
& e_{(k)}=w_{r}-w_{(r-1)} \\
& c e_{(k)}=e_{(k)}-e_{(k-1)}
\end{aligned}
$$

(2)'de yapılan hesaplamalar sonucunda elde edilen hata $\left(e_{(\mathrm{k})}\right)$ ve hata değişiminin $\left(c e_{(\mathrm{k})}\right)$ işaret analizinden sonra her bölge için hata ve hata değişimin işaretlerine bakılarak referans noktasından uzaklaşıp uzaklaşmadığına göre kurallar yazılır. Burada hata, bize istenilen referanstan uzaklaşıp uzaklaşılmadığını, hata değişimi ise hatanın hangi yönde olup olmadığını bildirir. İşaret analizi ise hata ve değişiminin referans noktasını aşıp aşmadığını gösterir [31], [32]. 


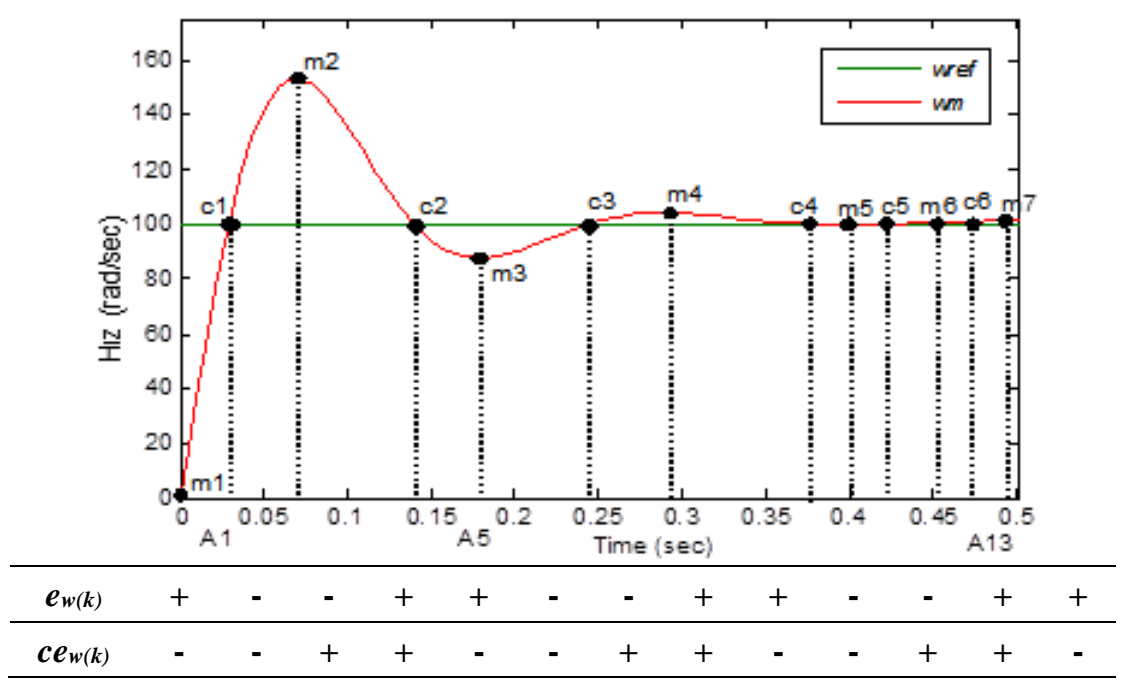

Şekil 3. SMDA motorunun $\mathrm{w}_{\mathrm{ref}}=100 \mathrm{rad} / \mathrm{sn}$ referans hızında dinamik analizi.

Şekil 3’te gösterilen motor hızının dinamik analizinde;

- c1, c2, c3, ..., c6: referans geçiş noktalarını yani sıfirdan geçme noktaları,

- $\mathrm{m} 1, \mathrm{~m} 2, \mathrm{~m} 3, \ldots, \mathrm{m} 7$ : referans uç noktalarını; pozitif, negatif ve max. aşımı,

- A1, A2, A3, ..., A13: referans aralıklarını ifade etmektedir.

Geçiş noktaları, uç noktaları ve referans aralıkların birleştirilmiş durumu Tablo 1'de verilmektedir.

Tablo 1. BMD’nin birleştirilmiş kural tablosu.

\begin{tabular}{|c|c|c|c|c|c|c|c|c|}
\hline \multirow{2}{*}{$\begin{array}{c}\text { Output } \\
u(t)\end{array}$} & \multicolumn{8}{|c|}{ Input e(t) } \\
\hline & & $\mathrm{nb}$ & $\mathrm{nm}$ & ns & $\mathrm{Z}$ & ps & $\mathrm{pm}$ & $\mathrm{pb}$ \\
\hline \multirow{7}{*}{$\begin{array}{l}\text { Input } \\
\text { ce }(t)\end{array}$} & $\mathrm{nb}$ & & & & $\mathrm{c} 1$ & & & \\
\hline & $\mathrm{nm}$ & $A 2$ & A6 & A10 & c3 & Al & $A 5$ & A9 \\
\hline & ns & & & & $c 5$ & & & \\
\hline & $\mathrm{z}$ & $m 2$ & $m 4$ & $m 6$ & $\mathrm{z}$ & $m 5$ & $m 3$ & $m 1$ \\
\hline & ps & & & & c6 & & & \\
\hline & $\mathrm{pm}$ & A3 & $A 7$ & A11 & $\mathrm{c} 4$ & A4 & $A 8$ & A12 \\
\hline & $\mathrm{pb}$ & & & & c2 & & & \\
\hline
\end{tabular}

Motor sürücüsünün süreç değişkeni olarak rotor hızı $(w)$, denetim değişkeni olarak motor akımı $\left(i_{a}\right)$ seçilmiştir. Sistem giriş değişkenleri referans hız ile motor hızı arasındaki hız hatası (e) ve hız hatasındaki değişim (ce) olarak tanımlanmıştır. Giriş işaretleri olan hata $\left(e_{(k)}\right)$ ve hata değişimi $\left(c e_{(k)}\right)$ için 7 , çıkış kontrol denetimi için ise 9 adet dilsel etiket kullanılarak 49 adet kural yazılmıştır. Bu dilsel ifadeler, girişler için Negative Big (nb), Negative Medium (nm), Negative Small (ns), Zero (z), Positive Small (ps), Positive Medium (pm) and Positive Big (pb), çıkış için ise bunlara ek olarak Negative very Big (nvb) and Positive very Big (pvb) kullanılmıștır. Bu sözel ifadeler kullanılarak denetim organı için oluşturulan giriș $(e, c e)$ ve çıkıș (control) üyelik fonksiyonları Şekil 4'te gösterilmiştir.
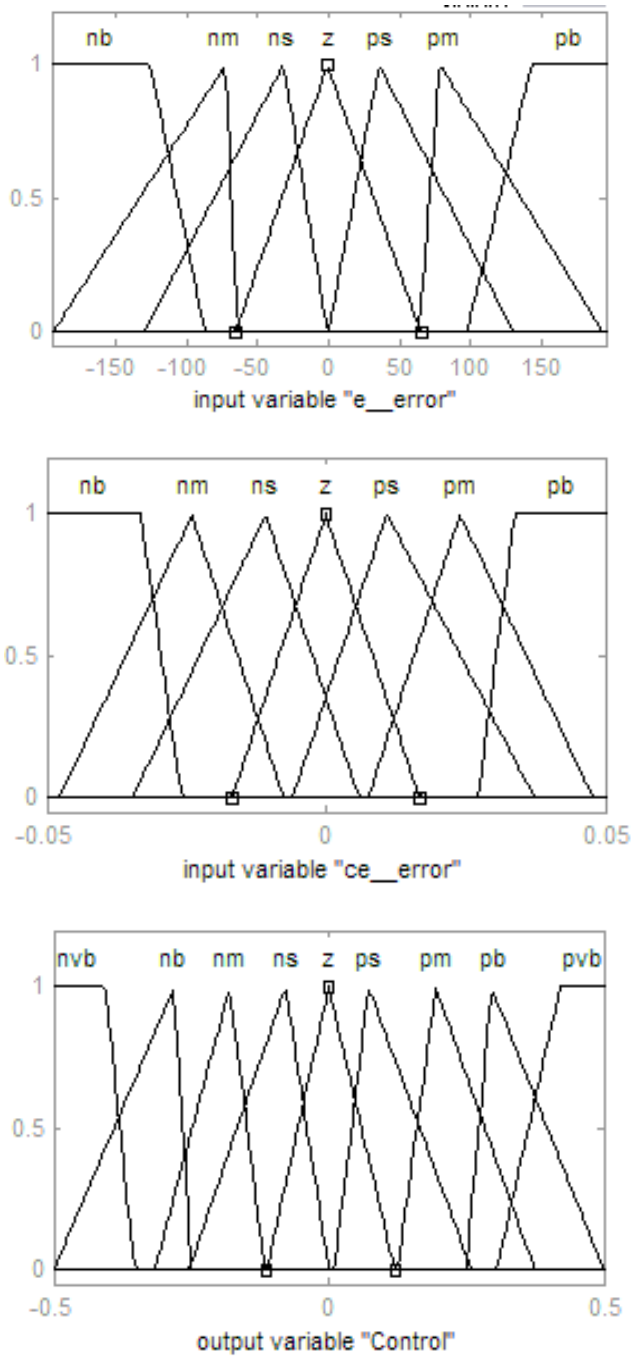

Şekil 4. Girişler (e error, ce_error) ve çıkış (Control) için oluşturulan üçgen ve trapez üyelik fonksiyonları. 
BM bloğunun bulanık denetim kuralları dinamik işaret analizindeki geçiş noktaları ve uç noktalarına göre Tablo 1'den faydalanılarak yazılmıştır. Eğer hata referansı aşmış ise akımı azalt, yok eğer daha referansa gelmemiş ise akımı arttır gibi azalt-arttır mantığı ile hız kontrolü amacıyla BM kontrol için yazılan 49 adet IF-THEN denetim kurallarının belirlenmesinde kullanılan bazı yorumlar şu şekildedir:

1) $\mathrm{A} 4, \mathrm{~A} 8, \mathrm{~A} 12$ aralıklarında $e=$ "+” ve $c e=$ "+”, hata pozitif ve artmaktadır. Dolayısıyla hatayı azaltmak için pozitif denetim girişi $u(t)$ verilmelidir.

2) $\mathrm{A} 1, \mathrm{~A} 5, \mathrm{~A} 9$ aralıklarında $\mathrm{e}=$ "“+” ve ce= “_”, hata hala pozitiftir ancak yavaş yavaş düşmektedir. Bu durumda denetim girişi $\mathrm{u}(\mathrm{t})$ küçük olacak şekilde kurulmalıdır.

3) A2, A6, A10 aralıklarında e= "_" ve ce= “-”, bu durum (1) deki durumun tam tersidir ve o zaman negatif denetim girişi verilmelidir.

4) $\mathrm{A} 3, \mathrm{~A} 7, \mathrm{~A} 11$ aralıklarında e= "-” ve ce= “+”, bu durum (2) deki durumun tam tersidir.

Yukarıdaki çıkarımlara göre referans aralıklarında elde edilen sözel kuralların listesi Tablo 2'de verilmiştir. Şekil 5 'te ise bulanık mantık denetleyici kural tabanının denetim yüzeyi ve Şekil 6'da BM denetleyicinin içyapısının blok şemas1 görülmektedir.
Tablo 2. Hız kontrolü için BMD IF-THEN kural tabanı.

\begin{tabular}{|c|c|c|c|c|c|c|c|c|}
\hline \multirow{2}{*}{$\begin{array}{c}\text { Output } \\
\text { Control } \\
u(t)\end{array}$} & \multicolumn{8}{|c|}{ input $e(t)$} \\
\hline & & nb & $\mathbf{n m}$ & ns & $\mathbf{Z}$ & ps & pm & pb \\
\hline \multirow{7}{*}{$\begin{array}{l}\text { input } \\
e c(t)\end{array}$} & nb & nvb & $\mathrm{nb}$ & $\mathrm{nb}$ & $\mathrm{nm}$ & ns & ns & Z \\
\hline & $\mathbf{n m}$ & $\mathrm{nb}$ & $\mathrm{nb}$ & $\mathrm{nm}$ & ns & ns & $\mathrm{Z}$ & ps \\
\hline & ns & $\mathrm{nb}$ & $\mathrm{nm}$ & ns & ns & $\mathrm{Z}$ & ps & ps \\
\hline & $\mathbf{Z}$ & $\mathrm{nm}$ & ns & ns & $\mathrm{Z}$ & ps & ps & $\mathrm{pm}$ \\
\hline & ps & ns & ns & $\mathrm{Z}$ & $\mathrm{pm}$ & $\mathrm{pm}$ & $\mathrm{pb}$ & $\mathrm{pb}$ \\
\hline & pm & ns & $\mathrm{Z}$ & $\mathrm{pm}$ & $\mathrm{pm}$ & $\mathrm{pb}$ & $\mathrm{pb}$ & $\mathrm{pvb}$ \\
\hline & pb & ps & ps & $\mathrm{pm}$ & $\mathrm{pb}$ & $\mathrm{pb}$ & pvb & $\mathrm{pvb}$ \\
\hline
\end{tabular}

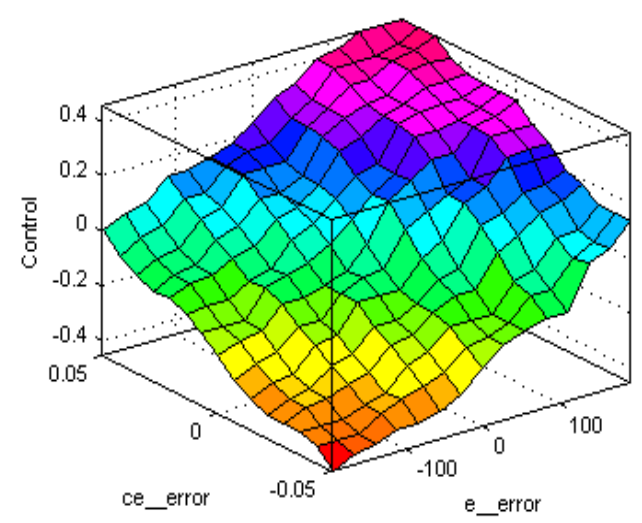

Şekil 5. Bulanık kuralların denetim yüzey görünümü.

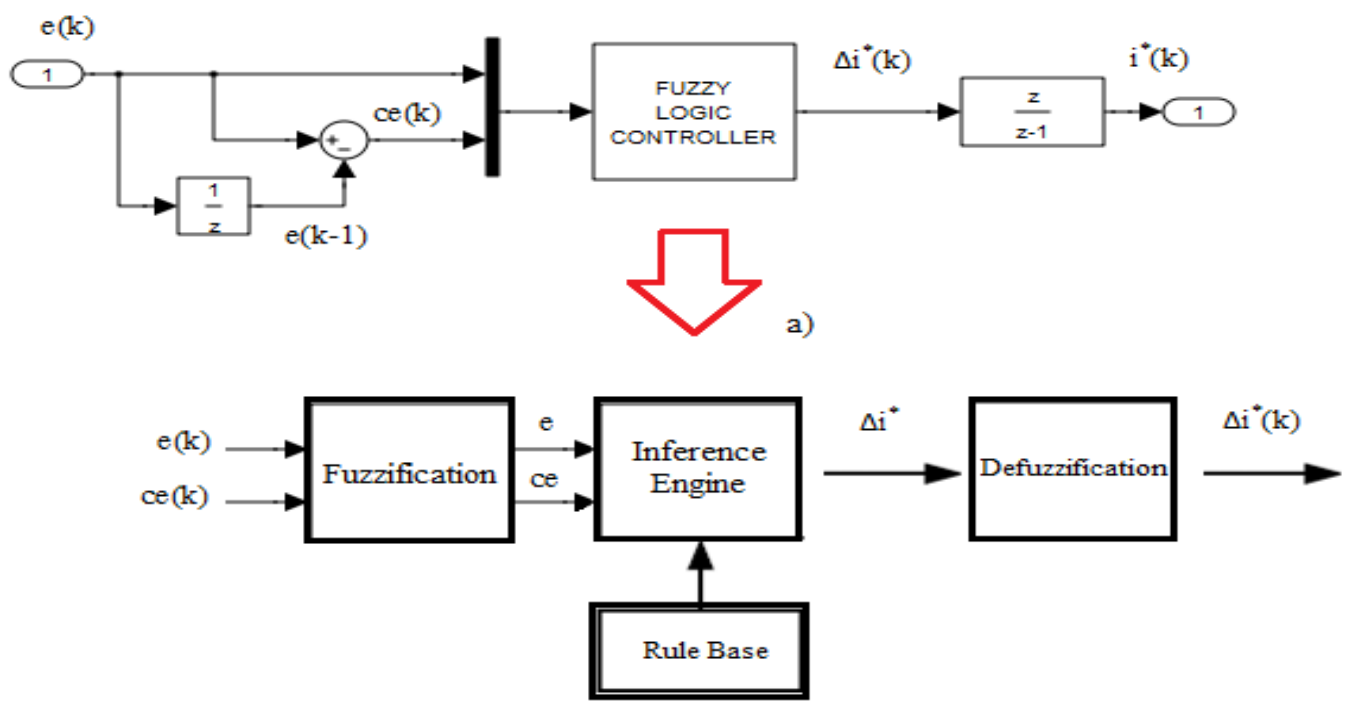

b)

Şekil 6. Bulanık Mantık Denetleyici bloğunun içyapısı.

Kural tabanı elde edildikten sonra bulanık çıkarım stratejisinin belirlenmesi gerekmektedir. Bulanık çıkarımı gerçekleştirmek için Max-Dot, Min-Max, Tsukamoto, Takagi-Sugeno gibi birçok teknik kullanılmaktadır. Bu uygulama için Min-Max bulanık çıkarım yöntemi seçilmiştir. Bulanık çıkarım işlemi sonucunda yine bulanık değerler elde edilmektedir. Bu değerlerin motor sürücüsünün kullanabileceği kesin değerlere çevrilmesi gerekmektedir. Durulama işleminde elde edilen bulanık değerler denetim işlevini yerine getirecek kesin değerler haline getirilmektedir. $\mathrm{Bu}$ işlemi gerçekleştirmek için birçok durulama yöntemi vardır [33]. Bu yöntemlerden endüstride en çok kullanılanı ve sabit ve değişken hız-yük değerlerinde ki performansları diğer yöntemlere nazaran daha iyi sonuçlar 
verdiği gözlemlenen COG Center of gravity (COG) durulama yöntemi kullanılmıştır [9], [14], [34].

\subsection{PI Denetimli Bulanık Mantık Denetleyici}

Sistem denetlenmesinde geleneksel PI denetleyiciler en yaygın ve en kullanışlı olanlarıdır. Orantı ve integral alma işlemleri bu denetleyicide birleştirilmiştir. Böylelikle orantı etkinin doğasındaki kararlılık ve integral etkinin kararlı durum hatasını azaltma avantajları birleştirilmiştir. SMDA motor kontrolü için PI denetimli BMD bloğunun içyapısı Şekil 7'de gösterilmiştir. PI tipi BMD'lerin performansları doğrusal ve birinci dereceden transfer fonksiyona sahip sistemler için oldukça iyidir. Fakat büyük ölü zaman doğrusalsızlığına sahip (mesela aşırı yüklemek gibi) ve transfer fonksiyonu yüksek dereceden olan sistemler için oldukça kötüdür (fazla aşma ve aşırı osilasyon gibi). Yapılan simülasyonlarda motoru aşırı yüklediğimizde aşma ve osilasyon olduğunu gözlemlenmiştir. Belirlenen kurallar bulanık tabanlı kontrol denetleyicinin aynısıdır.

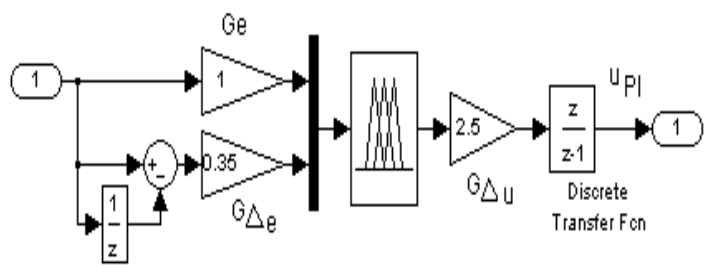

Şekil 7. SMDA motor kontrolü için Bulanık-PI denetimli bloğunun içyapısı.

Klasik PI denetleyiciler için denetleyici çıkışı,

$u(t)=K_{P} * e+K_{I} * \int e^{*} d t$

ile ifade edilmektedir. Burada $K_{P}$ ve $K_{I}$ sırasiyla oransal ve integral kazanç katsayılarıdır. Eğer Eşitlik (3)'teki ifadenin her iki tarafının türevi alınırsa Eşitlik (4)'teki denklem elde edilir.

$$
\begin{gathered}
\frac{d u(t)}{d t}=K_{P} *\left(\frac{d e}{d t}\right)+K_{I} * e(t) \\
\downarrow \quad \downarrow \\
\Delta u(t)=K_{P} * \Delta e+K_{I} * e(t)
\end{gathered}
$$

Yapılan hesaplama sonucundan da görülebildiği gibi PI denetimli BMD'nin çıkışı $\Delta u$ olmaktadır. Bu durumda PI tipli BMD’nin kurallarının yapısı sembolik olarak şöyledir:

"If $e_{(k)}=\left(\right.$ uygun değer) ve $\Delta e_{(k)}=($ uygun değer $)$ Then $u_{(k)}$ $=($ uygun de ger $)$ "

$\mathrm{Bu}$ durumda, $u_{(k)}$ denetleyici çıkışını elde etmek için denetleyicinin çıkışındaki değişme miktarı Eşitlik (5)'teki gibi denetleyicinin çıkış ifadesine eklenir.

$$
\left.\begin{array}{l}
\frac{d e}{d t} \rightarrow \Delta e \\
\frac{d u}{d t} \rightarrow \Delta u
\end{array}\right\} u_{(k)}=\Delta u_{(k)}+u_{(k-1)}
$$

\subsection{Kendini Ayarlayan Bulanık PI Denetleyici (KABPI)}

Eğer bir denetleyici değişen çevresel koşullara rağmen denetleme işlemini yerine getirebiliyorsa böyle denetleyicilere uyarlamalı denetleyiciler (adaptive) denir. Uyarlamalı BMD'lerin kendini ayarlayan (self-tuning) ve kendini organize eden (self-organizing) denetleyiciler gibi farklı tipleri vardır [35], [36]. Bu çalışmada geleneksel BMD'de sabit olan çıkışın ölçekleme faktörlerini denetlenmekte olan sistemin performansına bağlı olarak geliştirilmiş ikinci bir kural tabanına göre değiştirerek bulanık mantık denetleyiciler için kendini ayarlama tekniği ortaya çıkmaktadır [37]. Uyarlanan giriş ölçekleme faktörleri sabit tutularak mümkün olan en iyi performansa ulaşabilmek için çıkışın ölçekleme faktörleri ayarlanmıştır. Ayrıca BMD'lerde değiştirildikleri zaman denetleyicinin performansını etkileyen parametreler şunlardır;

1) Her değişsken için ölçekleme faktörleri (ÖF),

2) Dilsel değerlerinin anlamlarının ifade edildiği bulanık kümeler (ÜF),

3) Bulanık kurallar.

Adaptive olamayan BMD'lerde bu parametreler denetleyici kullanımda iken değişmez. Eğer bir BMD’de bu parametreler, denetleyici kullanımda iken sürekli olarak değişiyorsa bu denetleyiciye "Adaptif Bulanık Mantık Denetleyici (ABMD)" denir. Bir bulanık mantık denetleyicide ölçekleme faktörleri, üyelik fonksiyonları veya her ikisi de değiştirilerek denetleme yapılıyorsa buna "Kendini Ayarlayan Bulanık Mantık Denetleyici (KABMD)" denir ve blok şeması Şekil 8'de gösterilmiştir [38], [39]. Eğer BMD'nin ayarlanması kuralların değiştirilmesi ile yapılıyorsa buna da kendini organize eden BMD denir [40]. Kendini ayarlayan denetleyicinin kazancı sadece "Su" değil "Su. $\alpha$ " dur. Su'nun değeri geleneksel BMD'ler için sabittir. Ancak KABMD'nin kazancı denetleyici faaliyette iken sabit kalmaz. Denetlenen sistemin performansına bağlı olarak kazanç yenileme faktörü olan " $\alpha$ " ile her örnekleme periyodunda değiştirilir. Bu sürekli kazanç değişiminin amacı, denetleyicinin cevabını istenilen özelliklere uydurmaktır. Bu durumda hazırlanan denetleyici, basit bir geri beslemeli denetleyici olarak tanımlanmaktadır. " $\alpha$ " fonksiyonel olarak Eşitlik (6)'daki gibi ifade edilmektedir [39]-[41]

$\alpha(k)=f\left(e_{(k)}, d e_{(k)}\right)$ 


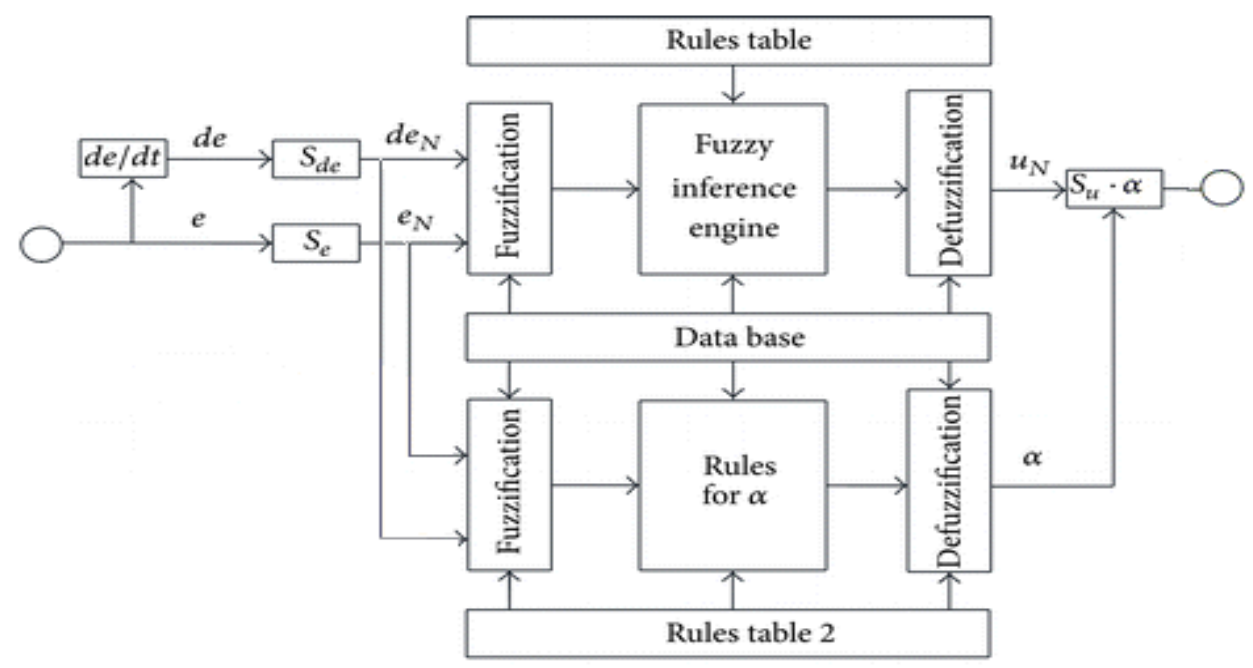

Şekil 8. Kendini Ayarlayan Bulanık Mantık Denetleyici (KABMD) blok diyagramı.

Eşitlik (6)'daki " f” fonksiyonu " $e$ " ve " $d e$ " ye bağlı doğrusal olmayan bir fonksiyondur. " $\alpha$ " nın " $e$ " ve " $d e$ " ye göre değişiminin nasıl olduğu Şekil 9'da gösterilmektedir. Ayrıca
Şekil 10 (a)'da sabit kazançlı BMD ve Şekil 10 (b)'de değişebilir kazançlı KABMD'nin denetleme yüzeyleri gösterilmiştir.

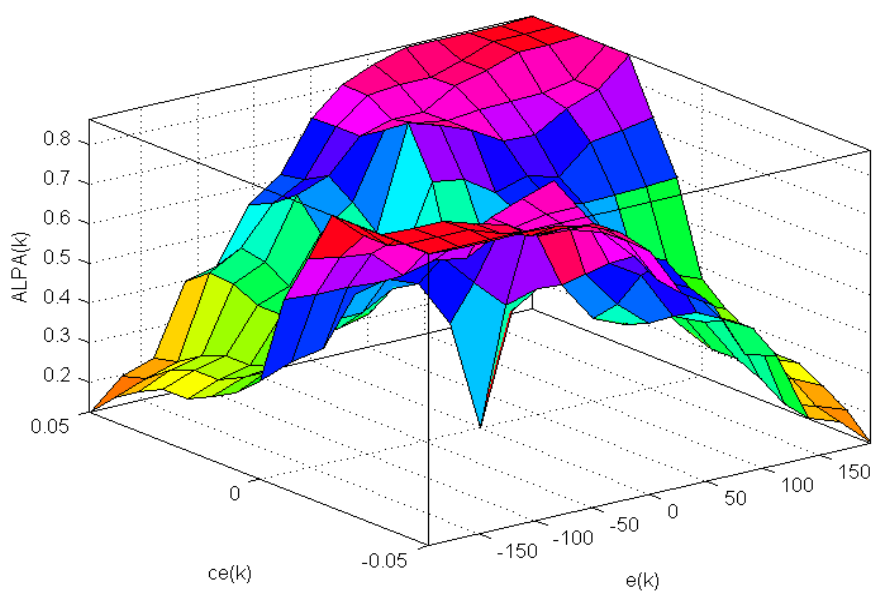

Şekil 9. " $\alpha$ " kazanç değiştirme faktörünün hata "e" ve hata değişimi "ce" ye bağl1 değişimi.

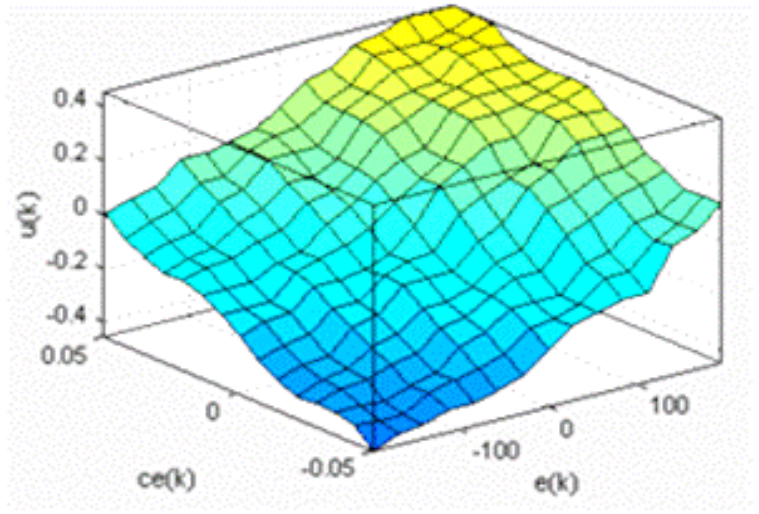

a)

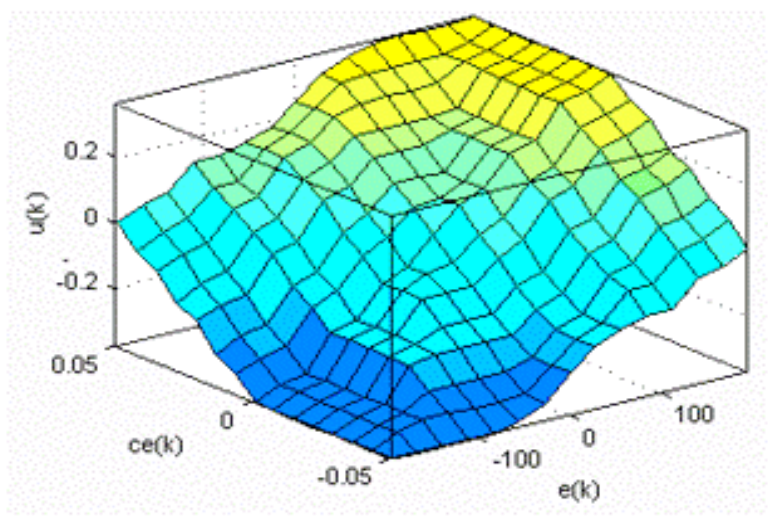

b)

Şekil 10. a) Sabit kazançlı BMD’ nin denetleme yüzeyi, b) KABMD Controller denetleme yüzeyi. 
Şekil 10'daki yüzeysel şekilleri dikkatle inceleyecek olursak, KABMD'ın doğrusalsızlı̆̆ı klasik BMD'ye göre daha az, yani geçişlerin daha yumuşak ve düzgün olduğu görülmektedir. Kendini ayarlayan denetleyici tasarımı denetleyici çıkışı “ $\alpha$ ” nın sürekli ve doğrusal olmayan değişimi ile oluşur. Belirtilmesi gereken en önemli nokta " $\alpha$ " nın herhangi bir sistem parametresine bağlı olmadığıdır. " $\alpha$ " nın değeri sadece sistemdeki ani değişimlere bağlıdır. Şekil 11 'de KABPI denetleyicinin blok şeması gösterilmiştir [39][42].

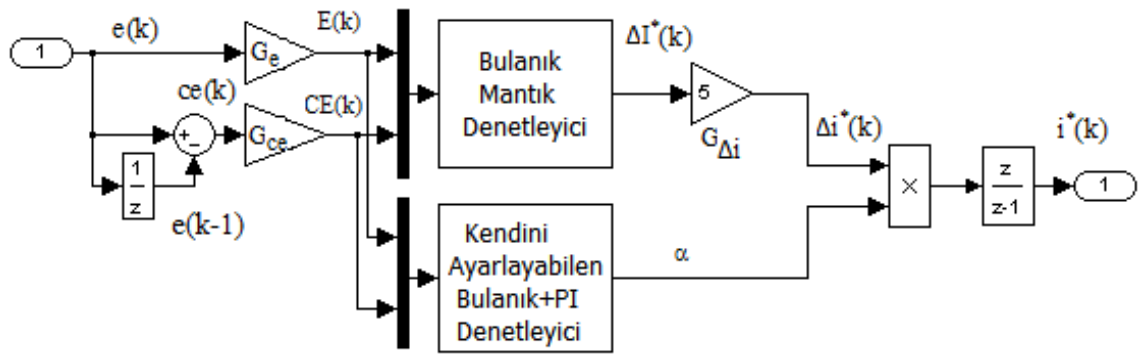

Şekil 11. SMDA motor kontrolü için KABPI denetleyici bloğunun içyapısı.

\section{BULGULAR}

Bu bölümde dayanıklı hız kontrolü için SMDA motorun BMD tabanlı akıllı kontrol yöntemleri ile geleneksel PI kontrol kullanılarak gerçekleştirilen bilgisayar benzetim sonuçları sunulmuştur. Bulanık mantık ve geleneksel PI kontrol arasında doğrusal ve doğrusal olmayan referans hızlarda, sabit ve ani değişen yüklerde performans karşılaştırmaları grafikler üzerinde gösterilmiştir. Sistemin davranışı üzerinde, dayanıklı hız kontrolü için farklı çalışma koşullarında gerçekleştirilen simülasyonlar, bulanık mantık tabanlı denetleyicilerin istenen referans hızı yakalamada ki hız hatası, aşımı, oturma zamanı ve yükselme zamanı $(M p$, ess, $t s, t r)$ değerleri geleneksel kontrol tekniklerine göre daha iyi olduğunu göstermektedir.

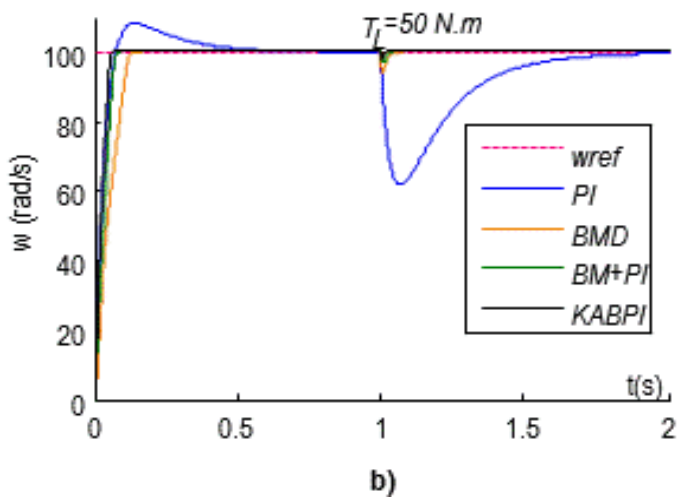

Şekil 12. wref $=100 \mathrm{rad} / \mathrm{s}$ sabit hızda (a) $\mathrm{T}_{\mathrm{L}}=20 \mathrm{~N} . \mathrm{m}$ ve (b) $\mathrm{T}_{\mathrm{L}}=50$ N.m ani yük değişimlerindeki hız-zaman grafiğgi.
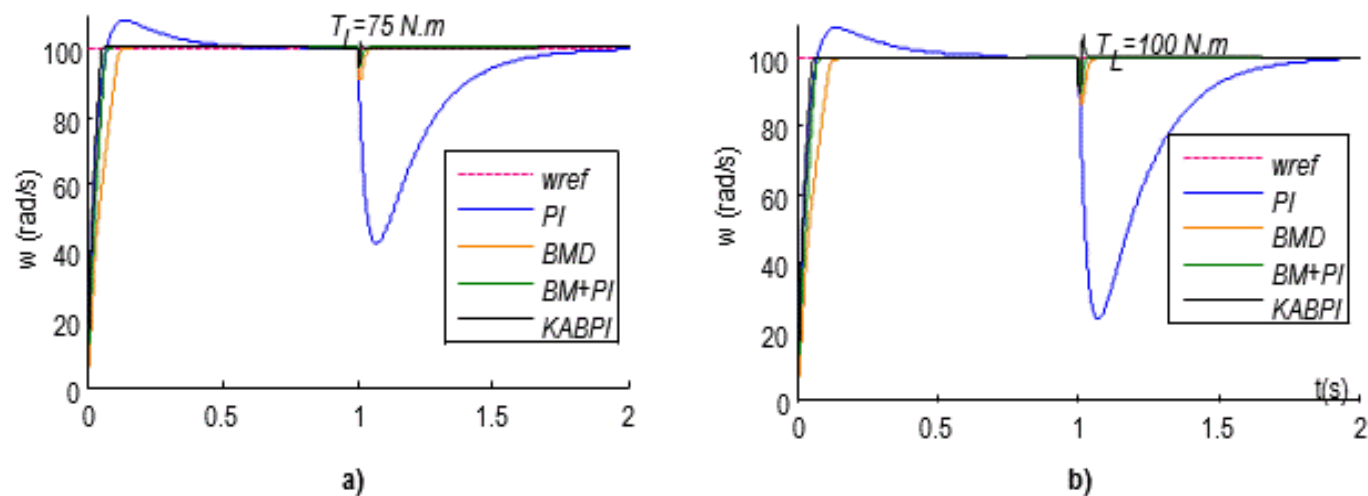

Şekil 13. $w r e f=100 \mathrm{rad} / \mathrm{s}$ sabit hızda $T_{L}=75$ N.m ve $T_{L}=100$ N.m ani yük değişimlerindeki hız-zaman grafiği. 


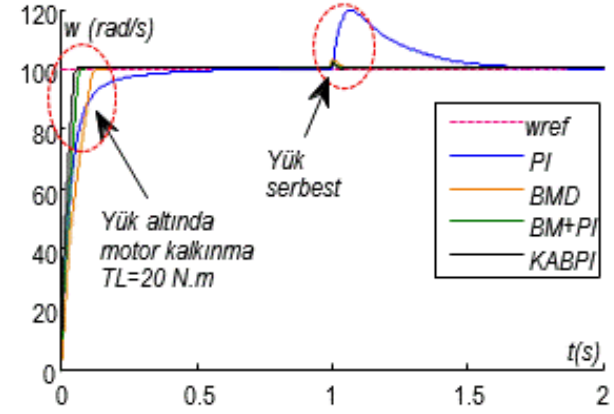

a)

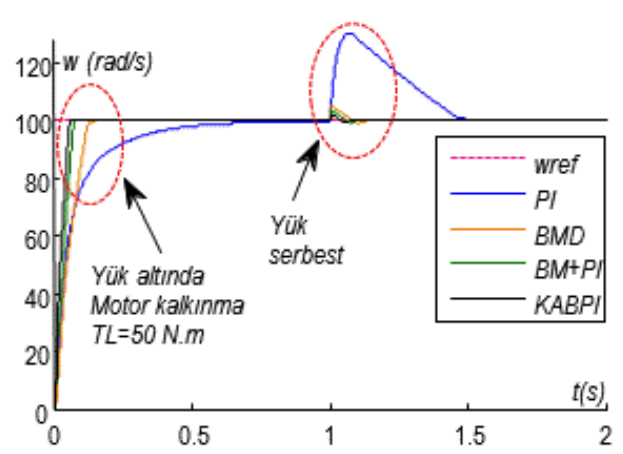

b)

Şekil 14. $w r e f=100 \mathrm{rad} / \mathrm{s}$ sabit hızda $T_{L}=20 \mathrm{~N} . \mathrm{m}$ ve $T_{L}=50 \mathrm{~N}$.m yük altındaki ilk hareket ve yükün bir zaman sonra serbest kalması durumunda ki denetleyicilerin performansı.

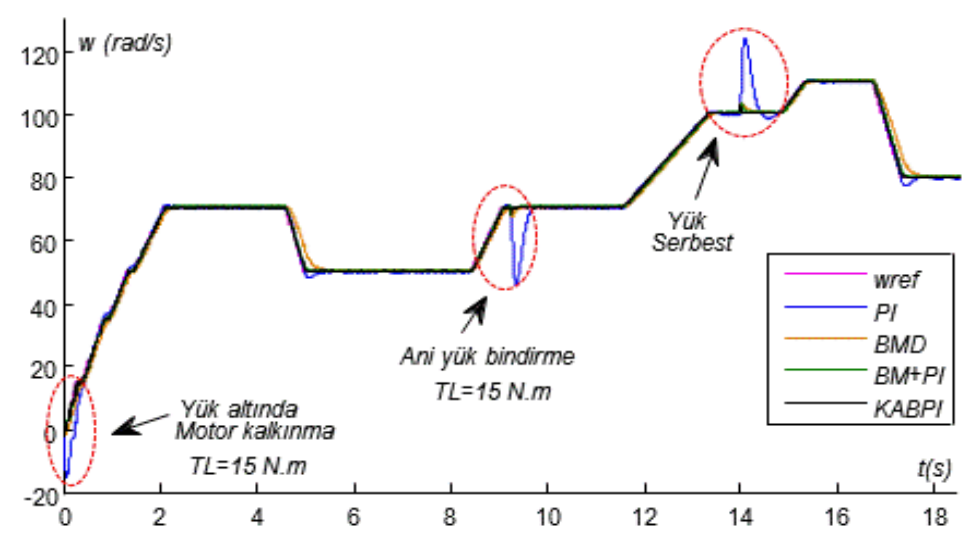

Şekil 15. SMDA motoru değişken referans hız Kentsel Sürüş Döngüsü (Extra Urban Driving Cycle (EUDC)) modunda yük altında kalkınma, ani yük bindirme ve yükün serbest kalması durumunda denetleyicilerin performansı.

Şekil 12, 13, 14 ve 15 'teki sonuçlardan görüldüğü üzere bulanı mantık tabanlı denetleyicilerin ilk hareket ve ani değișen yük altında referans hızla performans kıyaslaması yapıldığında en iyi olarak KABPI olduğu görülmektedir. PI tipli BMD'lerin performansları da integral elemanı içeren ve büyük ölü zamana sahip sistemlerde ve transfer fonksiyonu yüksek dereceden olan sistemler için oldukça kötü aşma ve osilasyon verdikleri yapılan analizde görülmüştür. PI, BMD, $\mathrm{BM}+\mathrm{PI}$ ve KABPI denetleyicilerin simülasyonlar sonucunda dayanıklı hız denetimi için gerekli kontrol performans kriterleri (Mp, ess, ts ve tr) Tablo 3 'te gösterilmiştir. Ayrıca Tablo 3'teki verilen değerlerin daha iyi anlaşılması için denetleyicinin performans değerleri grafik olarak Şekil 16 'da verilmiştir.

Tablo 3. wref=100 rad/s hızında motorun kalkınma ve değişen yük durumlarında denetleyicilerin performans değerleri.

\begin{tabular}{|c|c|c|c|c|c|}
\hline \multirow{2}{*}{ Yük Değerleri } & \multirow{2}{*}{ Denetleyici } & \multicolumn{2}{|c|}{ Yüksüz motorun ilk kalkınma } & \multicolumn{2}{|c|}{$t=1,5 \mathrm{sn}$ ani yük değişimi } \\
\hline & & $t r$ & $\% M p$ & ess & $t s$ \\
\hline \multirow{4}{*}{$T_{L}=20 \mathrm{~N} . \mathrm{m}$} & PI & 0,08 & 1 & 1,35 & 0,9 \\
\hline & BMD & 0,205 & 0 & 0,205 & 0,035 \\
\hline & $\mathrm{BM}+\mathrm{PI}$ & 0,083 & 0 & 0,095 & 0,0123 \\
\hline & KABPI & 0,0625 & 0 & 0,0625 & 0,007 \\
\hline \multirow{4}{*}{$T_{L}=50 \mathrm{~N} . \mathrm{m}$} & PI & 0,1 & 1,2 & 1,35 & 1,0341 \\
\hline & BMD & 0,205 & 0 & 0,205 & 0,05 \\
\hline & $\mathrm{BM}+\mathrm{PI}$ & 0,083 & 0 & 0,095 & 0,0246 \\
\hline & KABPI & 0,0625 & 0 & 0,0625 & 0,01 \\
\hline \multirow{4}{*}{$T_{L}=75 \mathrm{~N} . \mathrm{m}$} & PI & 0,12 & 1,5 & 1,35 & 1,098 \\
\hline & BMD & 0,205 & 0 & 0,205 & 0,15 \\
\hline & $\mathrm{BM}+\mathrm{PI}$ & 0,083 & 0 & 0,095 & 0,05 \\
\hline & KABPI & 0,0625 & 0 & 0,0625 & 0,02 \\
\hline \multirow{4}{*}{$T_{L}=100 \mathrm{~N} . \mathrm{m}$} & PI & 0,15 & 2 & 1,35 & 1,125 \\
\hline & BMD & 0,205 & 0 & 0,205 & 0,15 \\
\hline & $\mathrm{BM}+\mathrm{PI}$ & 0,083 & 0 & 0,095 & 0,085 \\
\hline & KABPI & 0,0625 & 0 & 0,0625 & 0,05 \\
\hline
\end{tabular}




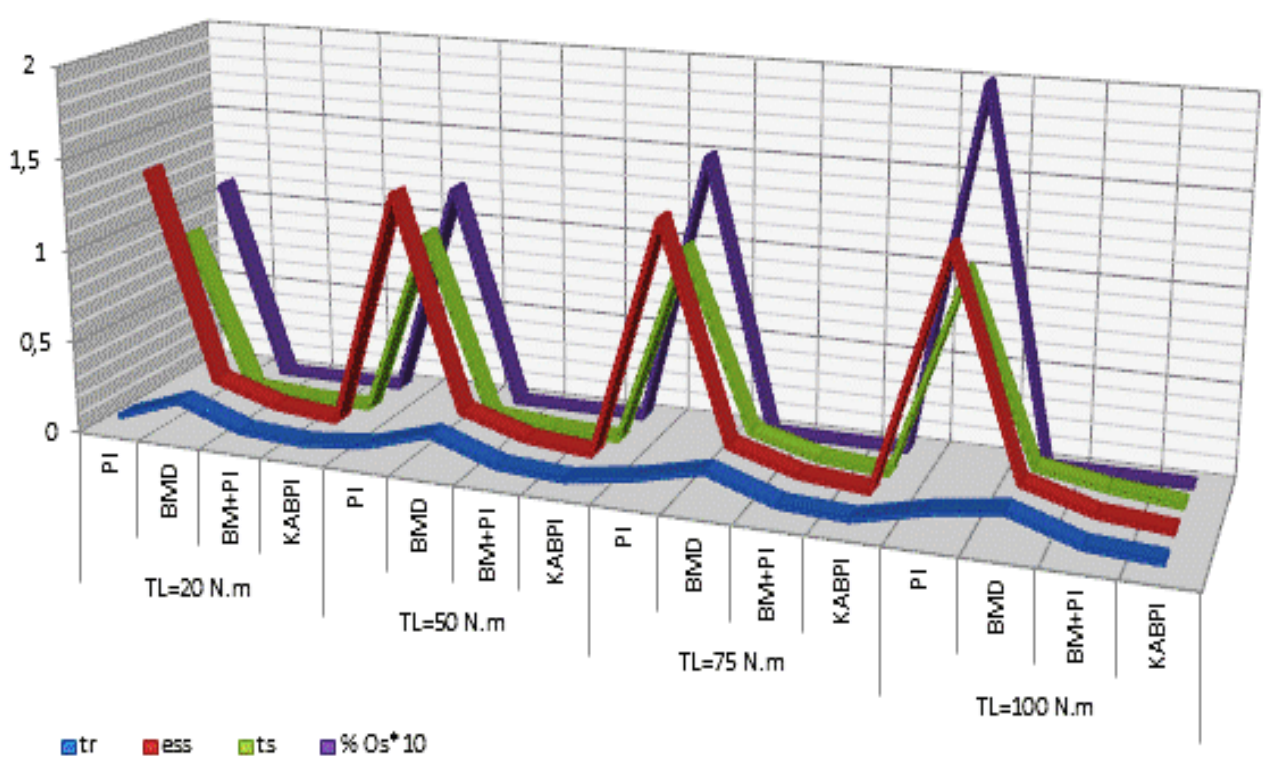

Şekil 16. Simülasyonlar sonucu motorun kalkınma ve değişen yük durumlarında denetleyicilerin performans değerleri.

\section{DEĞERLENDIRME VE SONUÇ}

Bu çalı̧̧mada yapılan analizlere göre, sabit-değişken hız ve yük şartlarında bulanık mantık tabanlı akıllı sistemlerin geleneksel kontrol sistemlerine nazaran daha iyi sonuçlar verdiği görülmüştür. Ayrıca KABPI kontrol sisteminin değişen tüm koşullara göre hız denetiminde BMD ve BM+PI'ye göre daha iyi performans verdiği gözlemlenmiştir. Tablo 4'te modellenen motorun parametreleri ve değerleri ile Şekil 17'de Matlab/Simulink programında tüm kontrol yöntemlerini içeren SMDA motor modeli verilmiştir.
Tablo 4. Matlab/Simulink SMDA motor parametreleri.

\begin{tabular}{|c|c|c|c|}
\hline Açıklama & Sembol & Birim & Değer \\
\hline Motor mil gücü & $P$ & $k W$ & 5 \\
\hline Armatür Gerilimi & $V_{m}$ & $V$ & 240 \\
\hline Armatür Direnci & $R_{m}$ & $\Omega$ & 0.5 \\
\hline Armatür Endüktansı & $L_{m}$ & $H$ & 0.012 \\
\hline Toplam atalet & $J_{m}$ & $\mathrm{kgm}^{2}$ & 0.0047 \\
\hline $\begin{array}{l}\text { Viskoz } \\
\text { Katsay1sı }\end{array}$ & $B_{m}$ & $\mathrm{Nms} / \mathrm{rad}$ & 0.002 \\
\hline Tork sabiti & $K_{e}$ & $N m / A$ & 0.5 \\
\hline Zit Emk Sabiti & $K_{m}$ & Vs/rad & 0.5 \\
\hline
\end{tabular}

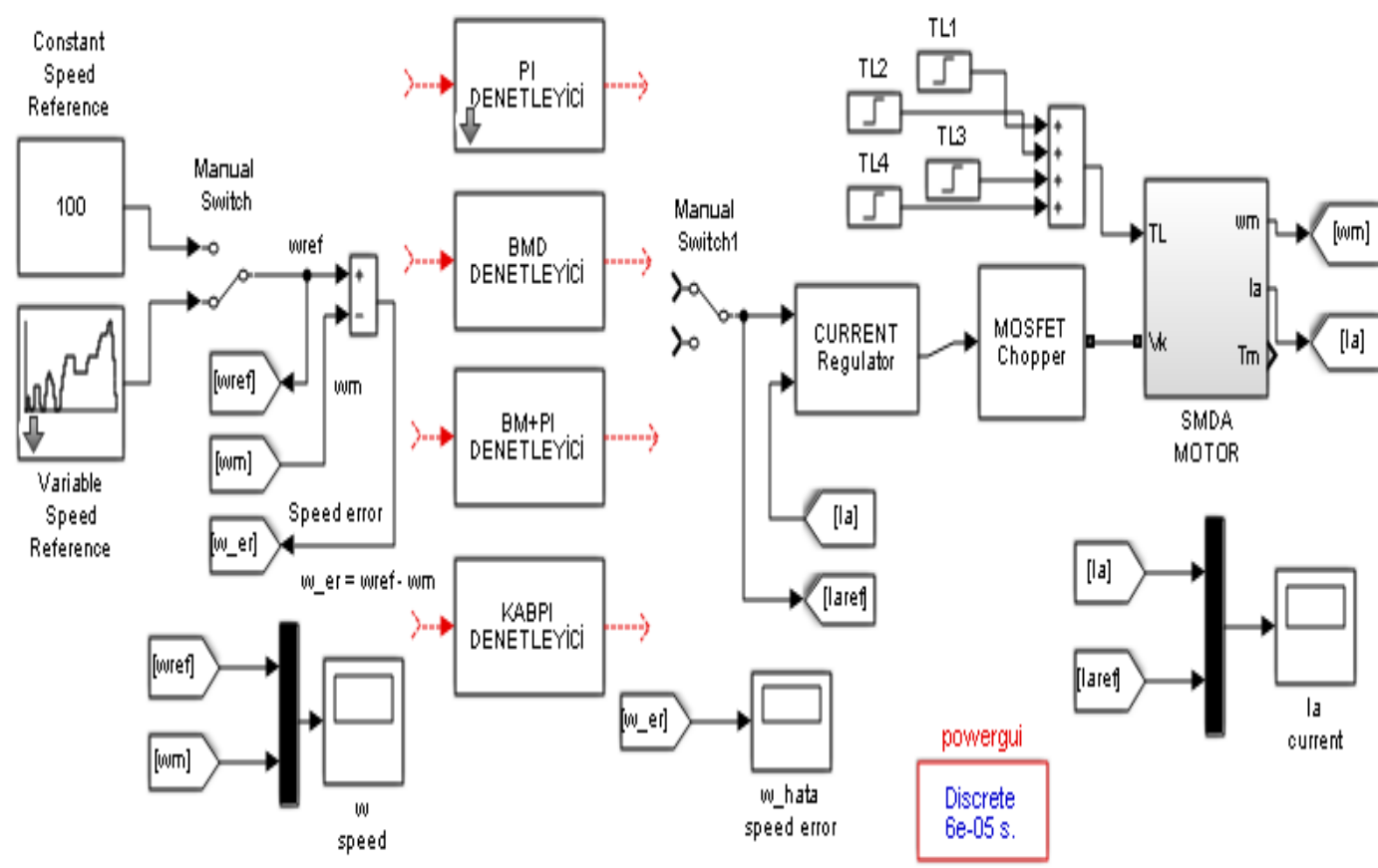

Şekil 17. SMDA motor kontrolü için tasarlanan sistemin Matlab/Simulink modeli. 


\section{KAYNAKÇA}

[1]. C. Rossi and A. Tonielli, "Robust control of permanent magnet motors: VSS techniques lead to simple hardware implementations," IEEE Trans. Ind. Electron., vol. 41, no. 4, pp. 451-460, 1994.

[2]. V. Sankardoss and P. Geethanjali, "PMDC Motor Parameter Estimation Using Bio-Inspired Optimization Algorithms," IEEE Access, vol. 5, pp. 11244-11254, 2017. [3]. A. Terki, A. Moussi, A. Betka, and N. Terki, "An improved efficiency of fuzzy logic control of PMBLDC for PV pumping system," Appl. Math. Model., vol. 36, no. 3, pp. 934-944, Mar. 2012.

[4]. V. Sankardoss and P. Geethanjali, "Parameter estimation and speed control of a PMDC motor used in wheelchair," Energy Procedia, vol. 117, pp. 345-352, Jun. 2017.

[5]. Hong-xing Wu, Shu-kang Cheng, and Shu-mei Cui, "A controller of brushless DC motor for electric vehicle," IEEE Trans. Magn., vol. 41, no. 1, pp. 509-513, Jan. 2005.

[6]. X. Wu, J. Liu, Y. Zhou, Q. Lv, and C. Hu, "Movement Control and Attitude Adjustment of Climbing Robot on Flexible Surfaces," IEEE Trans. Ind. Electron., vol. 65, no. 3, pp. 2618-2628, Mar. 2018.

[7]. D. Petković, M. Issa, N. D. Pavlović, L. Zentner, and Ž. Ćojbašić, "Adaptive neuro fuzzy controller for adaptive compliant robotic gripper,” Expert Syst. Appl., vol. 39, no. 18, pp. 13295-13304, Dec. 2012.

[8]. S. A. K. Mozaffari Niapour, S. Danyali, M. B. B. Sharifian, and M. R. Feyzi, "Brushless DC motor drives supplied by PV power system based on Z-source inverter and FL-IC MPPT controller," Energy Convers. Manag., vol. 52, no. 8-9, pp. 3043-3059, Aug. 2011.

[9]. S. S. Patil and P. Bhaskar, "Design and Real Time Implementation of Integrated Fuzzy Logic Controller for a High Speed PMDC Motor,' Int. J. Electron. Eng. Res., vol. 1, no. 1, pp. 13-25, 2009.

[10]. T. Özer, S. Kivrak, Y. Oğuz, and S. Kıvrak, "H Bridge DC Motor Driver Design and Implementation with Using dsPIC30f4011," Int. J. Innov. Res. Sci. Eng. Technol., vol. 6, no. 10, pp. 75-83, 2017.

[11]. A. M. Ali, A. Prof, A. H. Mohammed, A. Dr, and H. M. Alwan, "Tuning PID Controllers for DC Motor by Using Microcomputer," Int. J. Appl. Eng. Res., vol. 14, no. 1, pp. 202-206, 2019.

[12]. A. M. Zaki, M. El-Bardini, F. A. S. Soliman, and M. M. Sharaf, "Embedded two level direct adaptive fuzzy controller for DC motor speed control," Ain Shams Eng. J., vol. 9, no. 1, pp. 65-75, Mar. 2018.

[13]. R. Kandiban and R. Arulmozhiyal, "Speed Control of BLDC Motor Using Adaptive Fuzzy PID Controller," Procedia Eng., vol. 38, pp. 306-313, Jan. 2012.

[14]. M. Tuna, B. Fidan, S. Kocabey, and S. Görgülü, "Effective and Reliable Speed Control of Permanent Magnet DC (PMDC) Motor under Variable Loads," J Electr Eng Technol, vol. 10, no. 5, pp. 1921-718, 2015.

[15]. A. A. El-samahy and M. A. Shamseldin, "Brushless DC motor tracking control using self-tuning fuzzy PID control and model reference adaptive control," Ain Shams Eng. J., vol. 9, no. 3, pp. 341-352, Sep. 2018.

[16]. Y. Oğuz, "Fuzzy PI Control with Parallel Fuzzy PD Control for Automatic Generation Control of a Two-Area Power Systems," Gazi Univ. J. Sci. GU J Sci, vol. 24, no. 4, pp. 805-816, 2011.

[17]. J. Sharma, N. Gupta, P. Nain, M. Tech Scholar, and A. Professor, "Speed Control of Separately Excited DC Motor Using Fuzzy Logic Controller," Int. J. Tech. Res., vol. 2, no. 4, pp. 27-39, 2012.

[18]. E. Natsheh, K. A. Buragga, and S. Arabia, "Comparison between Conventional and Fuzzy Logic PID Controllers for Controlling DC Motors," IJCSI Int. J. Comput. Sci. Issues, vol. 7, no. 5, pp. 128-134, 2010.

[19]. S. R. Khuntia, S. P. Mohanty, and C. Ardil, "A Comparative Study of P-I, I-P, Fuzzy and Neuro-Fuzzy Controllers for Speed Control of DC Motor Drive," World Acad. Sci. Eng. Technol. Int. J. Electr. Comput. Eng., vol. 5, no. 5, pp. 714-718, 2011.

[20]. U. Kumar Bansal and R. Narvey, "Speed Control of DC Motor Using Fuzzy PID Controller," Adv. Electron. Electr. Eng., vol. 3, no. 9, pp. 1209-1220, 2013.

[21]. M. E. Fisher, A. Ghosh, and A. M. Sharaf, "Intelligent control strategies for permanent magnet DC motor drives," Proceedings of International Conference on Power Electronics, Drives and Energy Systems for Industrial Growth, IEEE, New Delhi, India, pp. 360-366, (1996).

[22]. M. G. Simoes, B. K. Bose, and R. J. Spiegel, "Fuzzy logic based intelligent control of a variable speed cage machine wind generation system," IEEE Trans. Power Electron., vol. 12, no. 1, pp. 87-95, 1997.

[23]. M. Venkata, G. Babu, and R. S. Naik, "Comparitive Analysis of P-I, I-P, PID and Fuzzy Controllers for Speed Control of DC Motor,” Int. Res. J. Eng. Technol., vol. 4, no. 10, pp. 500-504, 2017.

[24]. S. R. Khuntia, K. B. Mohanty, S. Panda, and C. Ardil, "A Comparative Study of PI , IP , Fuzzy and Neuro-Fuzzy Controllers for Speed Control of DC Motor Drive," Int. J. Electr. Syst. Sci. Eng., vol. 1, no. 1, pp. 1-5, 2010.

[25]. A. Varshney, D. Gupta, and B. Dwivedi, "Speed response of brushless DC motor using fuzzy PID controller under varying load condition,” J. Electr. Syst. Inf. Technol., vol. 4, no. 2, pp. 310-321, Sep. 2017.

[26]. K. Premkumar and B. V. Manikandan, "Bat algorithm optimized fuzzy PD based speed controller for brushless direct current motor," Eng. Sci. Technol. an Int. J., vol. 19, no. 2, pp. 818-840, Jun. 2016.

[27]. R. Arulmozhiyal, "Design and Implementation of Fuzzy PID controller for BLDC motor using FPGA,” 2012 IEEE International Conference on Power Electronics, Drives and Energy Systems (PEDES), IEEE, Bengaluru, India, pp. 1-6, Dec-(2012).

[28]. E. Hasan Dursun and A. Durdu, "Speed Control of a DC Motor with Variable Load Using Sliding Mode Control," Int. J. Comput. Electr. Eng., vol. 8, no. 3, pp. 219-226, 2016. [29]. I. Eminolu and .H. Alts, "A method to form fuzzy logic control rules for a PMDC motor drive system," Electr. Power Syst. Res., vol. 39, no. 2, pp. 81-87, Nov. 1996. 
[30]. I. Guney, Y. Oguz, and F. Serteller, "Dynamic behaviour model of permanent magnet synchronous motor fed by PWM inverter and fuzzy logic controller for stator phase current, flux and torque control of PMSM," IEMDC 2001. IEEE International Electric Machines and Drives Conference, IEEE, Cambridge, MA, USA, pp. 479-485, (2001).

[31]. İ. Eker and Y. Torun, "Fuzzy logic control to be conventional method," Energy Convers. Manag., vol. 47, no. 4, pp. 377-394, Mar. 2006.

[32]. İ. Eminoğlu and İ. H. Altaş, "The effects of the number of rules on the output of a fuzzy logic controller employed to a PM d.c. motor," Comput. Electr. Eng., vol. 24, no. 3-4, pp. 245-261, May 1998.

[33]. M. Namazov and O. Basturk, "DC motor position control using fuzzy proportional-derivative controllers with different defuzzification methods," J. Turkish Fuzzy Syst. Assoc., vol. 1, no. 1, pp. 36-54, 2010.

[34]. E. A. E.-H. M. Ramadan, M. El-Bardini, N. M. ElRabaie, and M. A. Fkirin, "Embedded system based on a real time fuzzy motor speed controller," Ain Shams Eng. J., vol. 5, no. 2, pp. 399-409, Jun. 2014.

[35]. M. Nour, O. Bouketir, and C. Eng Yong, "Self-Tuning of PI Speed Controller Gains Using Fuzzy Logic Controller," Mod. Appl. Sci., vol. 2, no. 6, p. p55, Nov. 2008.

[36]. H. B. Kazemian, "Comparative study of a learning fuzzy PID controller and a self-tuning controller," ISA Trans., vol. 40, no. 3, pp. 245-253, Jul. 2001.

[37]. E. Yeşil, M. Güzelkaya, and İ. Eksin, "Self tuning fuzzy PID type load and frequency controller," Energy Convers. Manag., vol. 45, no. 3, pp. 377-390, Feb. 2004.

[38]. M. Paksoy, R. Guclu, and S. Cetin, "Semiactive SelfTuning Fuzzy Logic Control of Full Vehicle Model with MR Damper,” Adv. Mech. Eng., vol. 6, p. 816813, Jan. 2014.

[39]. A. Karakaya and E. Karakas, "Performance Analysis of PM Synchronous Motors Using Fuzzy Logic And Self Tuning Fuzzy PI Speed Controls,” Arab. J. Sci. Eng., vol. 33, no. 1B, pp. 153-177, 2008.

[40]. Y. Guo and H. Long, "Self organizing fuzzy sliding mode controller for the position control of a permanent magnet synchronous motor drive," Ain Shams Eng. J., vol. 2, no. 2, pp. 109-118, Jun. 2011.

[41]. S. Sezer, S. Cetin, and A. E. Atalay, "Application of Self Tuning Fuzzy Logic Control to Full Railway Vehicle Model," Procedia Comput. Sci., vol. 6, no. 2011, pp. 487492, 2011.

[42]. A. K. Pal and I. Naskar, "Design of Self-Tuning Fuzzy PI controller in LABVIEW for Control of a Real Time Process," Int. J. Electron. Comput. Sci. Eng., vol. 2, no. 2, pp. 538-545, 2013. 